\title{
Multimodal treatment of pediatric patients with Askin's tumors: our experience
}

\author{
Silvia Triarico ${ }^{1 *}$, Giorgio Attinà ${ }^{1}$, Palma Maurizi ${ }^{1}$, Stefano Mastrangelo ${ }^{1}$, Lorenzo Nanni ${ }^{2}$, Vito Briganti ${ }^{3}$, Elisa Meacci ${ }^{4}$, \\ Stefano Margaritora ${ }^{4}$, Mario Balducci ${ }^{5}$ and Antonio Ruggiero ${ }^{1}$
}

\begin{abstract}
Background: We report our experience and outcomes about the management of Askin's tumors [AT], which are rare primitive neuroectodermal tumors (PNETs) that develop within the soft tissue of the thoracopulmonary region, typically in children and adolescents.

Methods: We retrospectively analyzed the charts of 9 patients affected by AT (aged 6-15 years), treated at the Paediatric Oncology Unit of Gemelli University Hospital in Rome between January 2001 and December 2016.

Results: All nine patients underwent to biopsy followed by neoadjuvant chemotherapy. At the end of the neoadjuvant chemotherapy, they underwent to surgical removal of the residual tumor. Five patients with positive tumor margins and/or necrosis $<90 \%$ received local radiotherapy. Two patients with metastasis received an intensified treatment, with the addition of high dose adjuvant chemotherapy followed by peripheral blood stem cells rescue. No statistically significant correlation was found between outcome and gender; the presence of any metastasis and the radiotherapy. The overall survival was 65.14 months (95\% confidence interval $[95 \% \mathrm{Cl}], 45.81-84.48$ ), and the 5 years survival was $60 \%$, at a median follow-up of 53.1 months.
\end{abstract}

Conclusion: Our study confirms that a multimodal treatment with surgery, chemotherapy, and radiotherapy may increase the survival in AT pediatric patients.

Keywords: Askin's tumors, Thoracopulmonary region, Polychemotherapy, Radiotherapy, Surgery

\section{Background}

Primitive neuroectodermal tumors (PNETs) are malignant and aggressive "small round cells" neoplasms that arise from the primitive nerve cells of the central nervous system (central PNETs), but at times, they can affect any peripheral nerve (peripheral PNETs) in the neck, chest wall, retroperitoneum, pelvis, and extremities [1].

In 1979, Askin et al. described for the first time, 20 cases of children and adolescents affected by PNETs of the thoracopulmonary region [2]. Since then, PNETs developed within the soft tissue of the thoracopulmonary region are referred to as "Askin's tumors" [AT]. In addition to this, AT occur typically in children and adolescents and they belong to the Ewing's sarcoma (EW) family because of

\footnotetext{
* Correspondence: silviatriarico@libero.it

${ }^{1}$ Paediatric Oncology Unit, A. Gemelli University Hospital, Catholic University

of Sacred Hearth, Largo A. Gemelli, 8, 00168 Rome, Italy

Full list of author information is available at the end of the article
}

their histological, immunohistochemically, cytogenetic, and phenotypic similarities [3].

Because of the rarity of this neoplasm, the approach to AT is complex and it may require a multidisciplinary management [4].

In this study, we describe our experience with nine children and adolescents affected by AT, evaluating patients' clinical characteristics, diagnosis assessment, multimodal treatment, and clinical outcomes.

\section{Methods}

We performed a retrospective analysis of children and adolescents affected by AT who were treated at the Paediatric Oncology Unit of Gemelli University Hospital in Rome between January 2001 and December 2016.

Data collected included gender, age at diagnosis, clinical presentation, lactate dehydrogenase (LDH) levels, radiological findings, histopathology, management, and outcome. 
At the admission, the patients showed different degrees of symptoms and clinical conditions. They underwent physical examination, biochemical, and radiological assessment. On all nine patients, a computed tomography (CT) scan was initially performed, which revealed the presence of the primitive chest mass. Subsequently, an 18F-flourodeoxyglucose positron emission tomography/ computed tomography (PET-CT), a bone scintigraphy, abdomen ultrasonography (US) scan, and a bilateral osteomedullary biopsy were performed, in order to detect the presence of any distant metastasis.

All patients were treated with a multidisciplinary approach, with the option of chemotherapy, high-dose chemotherapy and autologous stem cell transplantation, surgery, and radiotherapy.

The diagnosis was achieved with an ultrasound or CT-guided biopsy. All patients received a polychemotherapy treatment based on the EuroEwing99 protocol [5], which consists of 6 cycles VIDE (vincristine $1.5 \mathrm{mg} / \mathrm{kg} / \mathrm{d}$ at $\mathrm{d} 1$; ifosfamide $3 \mathrm{~g} / \mathrm{mq} / \mathrm{d}$ at $\mathrm{d} 1, \mathrm{~d} 2$, and $\mathrm{d} 3$; etoposide $150 \mathrm{mg} / \mathrm{mq} / \mathrm{d}$ at d1, $\mathrm{d} 2$, and $\mathrm{d} 3$; doxorubicine $20 \mathrm{mg} / \mathrm{mq} / \mathrm{d}$ at d1, d2, and d3) and 8 cycles VAI (vincristine $1.5 \mathrm{mg} / \mathrm{kg} / \mathrm{d}$ at d1; D-actinomycin $0.75 \mathrm{mg} / \mathrm{mq} / \mathrm{d}$ at d1 and d2; ifosfamide $3 \mathrm{~g} / \mathrm{mq} / \mathrm{d}$ at $\mathrm{d} 1$ and $\mathrm{d} 2$ ).

At the end of the neoadjuvant chemotherapy, they underwent surgical removal of the residual tumor. The aim of the histopathological report was to assess necrosis and the absence of surgical positive margins. The goal of the surgery was the complete resection, defined as the absence of positive tumor margins and/or necrosis > 90\% [6].

Local radiotherapy (44-54 Gy) was adopted for patients with positive tumor margins and/or tumoral necrosis $<90 \%$. Furthermore, metastatic patients received an intensified treatment, with the addition of high-dose adjuvant chemotherapy with busulphan $(3.75 \mathrm{mg} / \mathrm{mq} / \mathrm{d}$ at d6, d5, d4, and d3) and melphalan (140 mg/mq at d2), followed by peripheral blood stem cells rescue (at d0).
All statistical analyses were performed using the statistical software IBM SPSS $\odot$ version 20. Numerical variables are reported in mean and standard deviations (SD), whereas categorical variables are reported in numbers and percentages. Fisher's exact test was used for testing the association between categorical dichotomic variables and the survival outcome in a univariate model. A value of $p<0.05$ two-sided was considered statistically significant. A Kaplan-Meier curve was performed to calculate overall survival at 5 years.

\section{Results}

We reviewed data of nine patients affected by AT treated between January 2001 and December 2016. Patients' characteristics, treatments, and evolutions are summarized in Table 1

There were 5 (55.6\%) male patients and 4 (44.4\%) females, with a male to female ratio of 1:1.25. Age at presentation ranged between 6 and 15 years old (median age, 11 years).

Patients were mostly symptomatic at the diagnosis. Seven of them (77.8\%) presented a history of fever, with significant weight loss, cough, and dyspnea or chest pain; instead, the other two (22.2\%) showed a swelling or palpable mass on the chest wall or in the supraclavicular region. These symptoms usually developed rapidly in 10-30 days.

Patients typically presented with a very large thoracic tumor, with a median diameter of $9 \mathrm{~cm}$ (range, 5.5-16). The main lesion was reported in the Fig. 1, which showed CT scan of a 10-year-old girl with a large lesion (mean diameter $16 \mathrm{~cm}$ ) in the left hemithorax. The median volume was $166.4 \mathrm{~cm}^{3}$ (range 29.7-1404). In all nine patients, one or more ribs were involved, typically with erosion. Four patients $(44.4 \%)$ showed the involvement of soft tissues. Two (22.2\%) of these patients were metastatic at the bone, bone scintigraphy, and PET-CT detected bone metastasis. Bone marrow infiltration was absent in all these patients.

Table 1 Patients' characteristics, treatments, and follow-up

\begin{tabular}{|c|c|c|c|c|c|c|c|c|c|c|}
\hline $\begin{array}{l}\text { Patient } \\
\text { gender }\end{array}$ & $\begin{array}{l}\text { Age at diagnosis } \\
\text { (years) }\end{array}$ & $\begin{array}{l}\text { Tumor } \\
\text { size }(\mathrm{cm})\end{array}$ & $\begin{array}{l}\text { Tumor } \\
\text { volume }\left(\mathrm{cm}^{3}\right)\end{array}$ & $\mathrm{LDH}(\mathrm{UI} / \mathrm{L})$ & Metastasis & $\begin{array}{l}\text { Neoadjuvant/ } \\
\text { adjuvant CT }\end{array}$ & RT & $\begin{array}{l}\text { Relapse (months } \\
\text { after remission) }\end{array}$ & Survival & $\begin{array}{l}\text { Follow-up (months } \\
\text { since diagnosis) }\end{array}$ \\
\hline $1 \mathrm{M}$ & 12 & 11 & 29.7 & 475 & Yes & $\begin{array}{l}6 \text { VIDE + } 2 \text { VAl, } \\
\text { BUS/MELPH }\end{array}$ & No & No & Yes & 125 \\
\hline $2 M$ & 6 & 6 & 62.4 & 460 & No & $6 \mathrm{VIDE}+8 \mathrm{VAI}$ & Yes & No & No & 11.4 \\
\hline $3 F$ & 13 & 7 & 211.1 & 461 & No & $6 \mathrm{VIDE}+8 \mathrm{VAI}$ & Yes & No & Yes & 170.9 \\
\hline $4 M$ & 14 & 15 & 1404 & 560 & No & $6 \mathrm{VIDE}+8 \mathrm{VAI}$ & Yes & No & Yes & 76.5 \\
\hline $5 \mathrm{M}$ & 9 & 9 & 345.8 & 510 & No & $6 \mathrm{VIDE}+8 \mathrm{VAI}$ & No & Yes & No & 35.6 \\
\hline $6 \mathrm{~F}$ & 15 & 4.5 & 166.4 & 210 & No & $6 \mathrm{VIDE}+8 \mathrm{VAI}$ & Yes & No & Yes & 104.2 \\
\hline $7 \mathrm{~F}$ & 10 & 16 & 457.6 & 320 & No & $6 \mathrm{VIDE}+8 \mathrm{VAI}$ & Yes & No & No & 29 \\
\hline $8 \mathrm{M}$ & 11 & 7 & 117.9 & 280 & No & $6 \mathrm{VIDE}+8 \mathrm{VAI}$ & No & No & Yes & 28.7 \\
\hline $9 \mathrm{~F}$ & 6 & 5.5 & 50.5 & 420 & Yes & $\begin{array}{l}6 \mathrm{VIDE}+2 \text { VAl, } \\
\text { BUS/MELPH }\end{array}$ & No & No & Yes & 53.1 \\
\hline
\end{tabular}




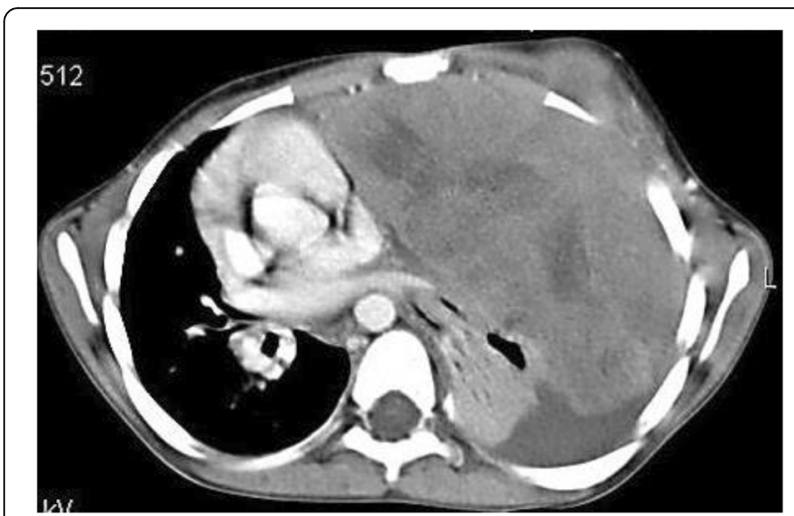

Fig. 1 CT scan of a 10-year-old girl revealed a large lesion (mean diameter $16 \mathrm{~cm}$ ) in the left hemithorax

Laboratory investigation were normal in all cases, except for an increased LDH in 8 patients $(88.9 \%$, median value $460 \mathrm{UI} / \mathrm{l}$; range $210-560$ ).

After a tumor biopsy, which typically revealed the presence of "small round cell tumour" positive for neuron-specific enolase (NSE) and for CD99, all patients received neoadjuvant chemotherapy, and subsequently, they underwent surgery for tumor resection. Five patients $(55.6 \%)$ with positive tumor margins and/or necrosis $<90 \%$ received local radiotherapy (44-54 Gy). Two patients (22.2\%) with metastatic disease received an intensified treatment, with the addition of high-dose adjuvant chemotherapy, including busulphan and melphalan, followed by peripheral blood stem cells rescue.

Seven patients $(77.8 \%)$ were disease-free at the end of the treatment, including the two metastatic patients. Two non-metastatic patients $(22.2 \%)$ showed a disease progression during the adjuvant chemotherapy, and finally, they died.

They died from pulmonary edema and insufficiency of respiration due to pulmonary metastatic disease.

Recurrent disease was reported in one non-metastatic patient (11.1\%) 7 months after the end of the treatment. This patient underwent second-line chemotherapy, without going into remission, and he finally died due to disease progression and finally for septic shock.

We found an overall survival of 65.14 months (95\% confidence interval [95\% CI], 45.81-84.48) and a 5-year survival of $60 \%$, at a median follow-up of 53.1 months, as exposed in the Fig. 2.

It was not found that there is a statistically significant correlation between the survival and the gender, the presence of any metastasis, and the radiotherapy, as Table 2 shows.

\section{Discussion}

AT belong to the family of Ewing's sarcoma (ES), which includes tumors of neuroectodermal origin that occur in bone and soft tissues (classical osseous ES, atypical

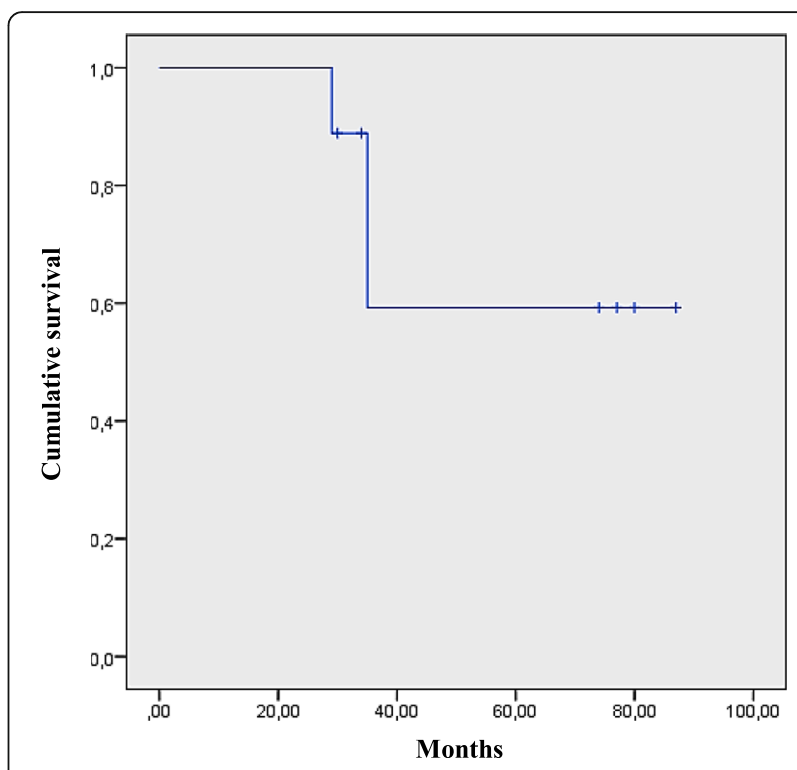

Fig. 25 years overall survival of our patients

extraosseous ES, PNET, and AT) [7]. AT are histologically identical to other PNETs, but they typically originate in the chest wall. They are the most common malignant chest wall tumors in children and young adults, followed by rhabdomiosarcoma, lymphoma, fibrosarcoma, osteosarcoma, and chondroma, as reported by Shamberger et al. [6, 8].

These neoplasms can develop at any age, but they are extremely rare and they occur more during the pediatric age than in adults [9]. Among our 9 patients, the younger was 6 years old and the oldest was 15 years old, and no significant difference was found in the prevalence between males or females.

Commonly, patients present a palpable and usually painful mass in the chest wall and/or fever, weight loss, cough, dyspnea, and even severe respiratory distress. From biochemical investigations, values of LDH are

Table 2 Correlation between the outcome and the sex, the presence of any metastasis, and the radiotherapy

\begin{tabular}{llllr}
\hline & No. of patients & $\%$ value & Survival outcome & $p$ value \\
\hline Sex & & & & 1.000 \\
Male & 5 & $55.6 \%$ & 3 & \\
Female & 4 & $44.4 \%$ & 3 & 0.500 \\
Metastasis & & & & \\
Yes & 2 & $22.2 \%$ & 2 & 0.524 \\
No & 7 & $77.8 \%$ & 4 & \\
RT & & & & \\
Yes & 5 & $55.6 \%$ & 4 & \\
No & 4 & $44.4 \%$ & 2 & \\
\hline
\end{tabular}

The significance level was determined at $p<0.05$ 
usually greater than normal and that seems to be associated with a worse prognosis [10].

Patients usually undergo radiological examination, such as X-rays and/or chest CT scans. The masses detected by chest CT scans are typically heterogeneous, with necrosis or cystic degeneration and hemorrhage, but rarely with calcifications, with a tendency to displace the adjacent organs and produce pleural effusions or rib erosions. CT scans are very useful for evaluating tumor extension during diagnosis, as well as for establishing the effects of chemotherapy and assessing tumor recurrence. Nevertheless, Sallustio et al. show that magnetic resonance imaging (MRI) may be better than CT for evaluating the tumor's local invasion and extension to pleura, lung, or diaphragm. Consequently, MRI may be considered complementary to CT scans especially for the evaluation of the extension of very large chest wall tumors [11].

Distant metastases are rare in AT, but they may occur in the lymphonodes, extrathoracic skeleton, liver, brain, retroperitoneum, bone marrow, and adrenal glands. PET-CT may be helpful for the characterization of the metabolic activity of the tumor and for the detection of distant metastases [12, 13].

The typical histological feature is the presence of small round cells, with Homer-Wright rosettes and immunohistochemical positivity for several neural markers, such as NSE and CD99. The identification of chromosomal translocation $\mathrm{t}(11 ; 22)(\mathrm{q} 24, \mathrm{q} 12)$ and the detection of proto-oncogenes (n-myc, c-myb, c-ets-1) may be additional diagnostic criteria [14].

The prognosis of AT reported in the literature is very poor. In our experience, we did not find a significant correlation between the outcome and the categorical variables analyzed (gender, the presence of any metastasis, and radiotherapy). In addition to this, we observed that a prompt diagnosis and an intensive treatment are crucial for the patients' survival.

A complete surgical resection with wide margins can give better prospects of survival; however, this is not always possible due to the anatomical complexities of the chest. As a consequence, surgery must always be associated with chemotherapy (including ifosfamide or cyclophosphamide, vincristine, etoposide, D-actinomycin, and doxorubicine) and radiotherapy (usually 44-54 Gy) [15].

Neoadjuvant chemotherapy may have important benefits, such as the chance of treating distant metastases, a lower risk of intraoperative tumor rupture and tumor cells dissemination, and an enhanced probability of less extensive surgery as well as preserving a better post-operative function $[16,17]$. In their study, Bacci et al. demonstrated that, in cases of surgically treated patients with non-metastatic EW, the most important prognostic factor seems to be neoadjuvant chemotherapy-induced necrosis, with better clinical outcomes in patients with good necrosis $(90 \%)[18,19]$.

Several studies showed that the poor prognosis of high-risk EW patients (including metastatic patients) may be improved by high-dose chemotherapy with busulfan and melphalan followed by peripheral blood stem cell transplantation [20].

Radiotherapy is an active modality for assuring local control, used as definitive radiotherapy in inoperable tumors or in combination with surgery (either pre- or post-surgery). Definitive radiotherapy is performed in inoperable lesions only. Inoperability is given in large tumors that cannot be completely resected and in tumors in critical sites where complete surgery would be mutilating or associated with a high risk of severe complications. The definitive radiotherapy is to start following course 6 of the induction regimen for patients in the conventional arms, or 8-10 weeks after stem cell reinfusion in patients of the high-dose chemotherapy with busulfan and melphalan $[5,21]$.

The results of the study conducted on eight patients with AT by Christianses et al. evidenced that AT require an aggressive multimodal treatment, consisting of preand post-operative chemotherapy, radical surgical resection, and postoperative irradiation [22]. In addition to this, in a study conducted among 104 patients with AT, Laskar et al. demonstrated that the combination of neoadjuvant and adjuvant chemotherapy, surgery, and radiotherapy resulted in optimal outcome [23].

\section{Conclusions}

In our study, we confirm that surgical resection is essential for the treatment of AT pediatric patients. Moreover, a multimodal management, including surgery, chemotherapy, and radiotherapy, should be used for improving the overall survival.

\section{Abbreviations \\ AT: Askin's tumors; Cl: Confidence interval; CT: Computed tomography; \\ ES: Ewing's sarcoma; LDH: Lactate dehydrogenase; MRI: Magnetic resonance imaging; NSE: Neuron-specific enolase; PET-CT: Positron emission \\ tomography/computed tomography; PNETs: Primitive neuroectodermal tumors; US: Ultrasonography; VAl: Vincristine, D-actinomycin, ifosfamide; VIDE: Vincristine, ifosfamide, doxorubicine, etoposide}

\section{Acknowledgements}

Fondazione per l'Oncologia pediatrica.

\section{Availability of data and materials}

The datasets used and/or analyzed during the current study are available from the corresponding author on reasonable request.

\section{Authors' contributions}

GA, ST, PM, and MB analyzed and interpreted the patient clinical data. VB, SM, EM, and LN described the surgical data. ST and AR were major

contributors in writing the manuscript. All authors read and approved the final manuscript.

Ethics approval and consent to participate

Compliance with ethical standards. 


\section{Consent for publication}

Not applicable.

\section{Competing interests}

The authors declare that they have no competing interests.

\section{Publisher's Note}

Springer Nature remains neutral with regard to jurisdictional claims in published maps and institutional affiliations.

\section{Author details}

${ }^{1}$ Paediatric Oncology Unit, A. Gemelli University Hospital, Catholic University of Sacred Hearth, Largo A. Gemelli, 8, 00168 Rome, Italy. ${ }^{2}$ Pediatric Surgery Unit Gemelli University Hospital, Catholic University of Sacred Heart, Rome, Italy. ${ }^{3}$ Pediatric Surgery Unit, San Camillo Forlanini Hospital, Rome, Italy. ${ }^{4}$ Thoracic Surgery Unit, Gemelli University Hospital, Catholic University of Sacred Heart, Rome, Italy. ${ }^{5}$ Radiotherapy Unit, Gemelli University Hospital, Catholic University of Sacred Heart, Rome, Italy.

Received: 27 April 2018 Accepted: 26 June 2018

Published online: 13 July 2018

\section{References}

1. Mouna K, Abderrahmane M, Li N, et al. Peripheral primitive neuroectodermal tumors of the spine: a case report and review of the literature. BMC Res Notes. 2016;9:43.

2. Askin FB, Rosai J, Sibley RK, et al. Malignant small cell tumor of the thoracopulmonary region in childhood: a distinctive clinicopathologic entity of uncertain histogenesis. Cancer. 1979;43:2438-51.

3. Parikh M, Samujh R, Kanojia RP, et al. Peripheral primitive neuroectodermal tumor of the chest wall in childhood: clinico-pathological significance, management and literature review. Chang Gung Med J. 2011;34:213-7.

4. Purnima Devi L, Ritesh K, Jyoti Prasad K, et al. Locally advanced Askin's tumour in a child - a rare case report and review of the literature. Indian $J$ Surg Oncol. 2015;6:288-91.

5. Euro-Ewing 99. EUROpean Ewing tumor working initiative of national groups. Version 3a, 14th September 2010.

6. Shamberger RC, Grier HE. Ewing's sarcoma/primitive neuroectodermal tumor of the chest wall. Semin Pediatr Surg. 2001;10:153-60.

7. van den Berg $H$, van Rijn RR, Merks JH. Management of tumors of the chest wall in childhood: a review. J Pediatr Hematol Oncol. 2008;30:214-21.

8. Katsenos S, Nikopoloulou M, Kokkonouzis I, et al. Askin's tumor: a rare chest wall neoplasm. Case report and short review. Thorac Cardiovasc Surg. 2008; 56:308-10

9. Jeong JY, Kim SY, Jeong DC, et al. A small Askin's tumor presenting with early onset of chest pain. World J Surg Oncol. 2015;13:112.

10. Li S, Yang $\mathrm{Q}$, Wang $\mathrm{H}$, et al. Prognostic significance of serum lactate dehydrogenase levels in Ewing's sarcoma: a meta-analysis. Mol Clin Oncol. 2016:5:832-8.

11. Sallustio G, Pirronti T, Lasorella A, et al. Diagnostic imaging of primitive neuroectodermal tumour of the chest wall (Askin tumour). Pediatr Radiol. 1998;28:697-702

12. Kara Gedik G, Sari O, Altinok T, et al. Askin's tumor in an adult: case report and findings on 18F-FDG PET/CT. Case Rep Med. 2009:2009:517329.

13. Kumar PV. Fine needle aspiration cytologic findings in malignant small cell tumor of the thoracopulmonary region (Askin tumor). Acta Cytol. 1994;38: 702-6.

14. Laine M, Ghorfi IA, Lambatten D, et al. Rapidly fatal Askin's tumor: a case report and literature review. Pan Afr Med J. 2014;18:104.

15. Zhang KE, Lu R, Zhang $P$, et al. Askin's tumor: 11 cases and a review of the literature. Oncol Lett. 2016;11:253-6.

16. Veronesi G, Spaggiari L, De Pas T, et al. Preoperative chemotherapy is essential for conservative surgery of Askin tumors. J Thorac Cardiovasc Surg. 2003;125:428-9.

17. Picci P, Rougraff BT, Bacci $G$, et al. Prognostic significance of histopathologic response to chemotherapy in nonmetastatic Ewing's sarcoma of the extremities. J Clin Oncol. 1993;11:1763-9.

18. Bacci G, Ferrari S, Bertoni F, et al. Prognostic factors in nonmetastatic Ewing's sarcoma of bone treated with adjuvant chemotherapy: analysis of 359 patients at the Istituto Ortopedico Rizzoli. J Clin Oncol. 2000;18:4-11.
19. Oberlin O, Rey A, Desfachelles AS, et al. Société Française des Cancers de I'Enfant. Impact of high-dose busulfan plus melphalan as consolidation in metastatic Ewing tumors: a study by the Société Française des cancers de I'Enfant. Pediatr Blood Cancer. 2007:49:190-5.

20. Al-Faris N, Al Harbi T, Goia C, et al. Does consolidation with autologous stem cell transplantation improve the outcome of children with metastatic or relapsed Ewing sarcoma? Pediatr Blood Cancer. 2007;49:190-5.

21. Dunst J, Sauer R. Therapy of Ewing's sarcoma. Strahlenther Onkol. 1993;169: 695-708.

22. Christiansen S, Semik M, Dockhorn-Dworniczak B, et al. Diagnosis, treatment and outcome of patients with Askin-tumors. Thorac Cardiovasc Surg. 2000; 48:311-5.

23. Laskar S, Nair C, Mallik S, et al. Prognostic factors and outcome in AskinRosai tumor: a review of 104 patients. Int J Radiat Oncol Biol Phys. 2011;79: 202-7.

\section{Ready to submit your research? Choose BMC and benefit from:}

- fast, convenient online submission

- thorough peer review by experienced researchers in your field

- rapid publication on acceptance

- support for research data, including large and complex data types

- gold Open Access which fosters wider collaboration and increased citations

- maximum visibility for your research: over $100 \mathrm{M}$ website views per year

At BMC, research is always in progress.

Learn more biomedcentral.com/submissions 